\title{
A EFICÁCIA MATERIAL DO "ACESSO À INTERNET" COMO UM DIREITO FUNDAMENTAL NO ORDENAMENTO PÁTRIO: INCLUSÃO DIGITAL E POLÍTICAS PÚBLICAS NO BRASIL ${ }^{*}$
}

Guilherme Tomizawa* $^{* *}$

\section{RESUMO}

O presente trabalho acadêmico, tem o objetivo de realizar um estudo e análise dos direitos de abstenção e prestação (em especial esse último) e a eficácia do uso da internet como uma garantia fundamental no direito brasileiro. Tratar-se-á, inicialmente sobre a educação e as novas tecnologias, se provável tal união. Logo após verificar-se-á a possibilidade do acesso à internet como um direito fundamental. Finalmente mostrará a materialidade dos telecentros sendo utilizados como exemplo de políticas públicas de inclusão digital no Brasil.

Palavras chave: Acesso, internet, direito fundamental, inclusão digital, telecentros, políticas públicas.

\section{LA EFICACIA DE MATERIAL DEL "ACCESO A INTERNET" COMO DERECHO FUNDAMENTAL EN EL DERECHO PATRIO: LA INCLUSIÓN DIGITAL Y POLÍTICA PÚBLICA EN BRASIL}

\section{RESUMEN}

El presente trabajo da cuenta de los resultados del análisis de la prestación y el uso eficaz de Internet como una garantía fundamental según la ley brasileña. El acceso a internet se analisa como un principio vinculado a la educación y a las nuevas tecnologías. Se defenderá la

* El presente artículo constitui uma revisão de investigações sobre e tema.

** Professor de graduação em Direito Eletrônico pela OPET. Professor da pós-graduação em direito eletrônico pela UP, IPOG e Verbo Jurídico. Mestre em Direito Público pela UGF. Aluno regular do curso de Doutorado em Direito Civil pela UBA. 
tesis, a partir de la revisión de las fuentes sobre el tema, de que la posibilidad de acceder a Internet constituye un derecho fundamental. Finalmente se mostrará el funcionamento de los telecentros que constituyen un ejemplo de las políticas públicas para la inclusión digital en Brasil.

Palabras claves: Acceso a internet, derecho fundamental, inclusión digital, telecentros, políticas púbicas.

\title{
THE EFFECTIVENESS OF "INTERNET ACCESS" AS A FUNDAMENTAL RIGHT: DIGITAL INCLUSION AND PUBLIC POLICY IN BRAZIL
}

\begin{abstract}
This research focuses on the analysis of the right to provide and to use the internet effectively as a fundamental guarantee in Brazilian law. First, it deals with the relation of internet access, education and new technologies. Second, it defends the thesis that Internet access may be considered as a fundamental right. Finally, it points out the importance of telecenters, which are used as an example of public policies for digital inclusion in Brazil.
\end{abstract}

Key words: Access, Internet, fundamental right, digital inclusion, telecenters, public policies.

\section{INTRODUÇÃO}

\section{"Nunca é tarde para aprender, você se sente uma pessoa realizada' \\ (Terezinha Dena, aluna de informática aos 70 anos de idade)}

Desde Gutenberg até o advento da Internet $^{1}$ passamos pelas três

\footnotetext{
1 "Em 1969, meados da guerra fria, o projeto militar ARPANET da agência de projetos avançados (ARPA) do Departamento de Defesa norte-americano confiou à Rand Corporation um sistema de telecomunicações que garantisse que um ataque russo não interrompesse as comunicações dos EUA (PAESANI, 2000, p.25). Em 1989 nasceu a www (World Wide Web), uma teia de alcance mundial composta por hipertextos que se transformou numa nova ferramenta de comunicação e avanço na aldeia global (...)". Cf. TOMIZAWA, G. (2008). A invasão de privacidade através da internet. Curitiba: JM Livraria Jurídica, p. 25.
} 
principais eras ${ }^{2}$ que são constantemente pano de fundo para se traçar a história e a evolução do homem e das tecnologias. (Scorzelli, 1997, p. 8).

Dentre todas as revoluções e processos históricos - a "era da informação", atualmente é a mais interessante e mais peculiar no contexto contemporâneo do cenário mundial. Por razões óbvias quando pensamos em internet, a primeira palavra que vem em nossas mentes é a expressão "informação". Tal informação pode levar ao "conhecimento específico", que por sua vez nos remete à almejada "educação". A educação é um direito social estampado nos artigos 6 e 205 da Constituição Federal Brasileira de $1988^{3}$. Aí repousaria a grande celeuma entre os juristas e estudiosos dessa novel área, se seria realmente necessário a positivação do "acesso à internet", sendo galgado à um direito fundamental no catálogo de direitos fundamentais? Tal direito já estaria implícito no artigo supracitado, não havendo necessidade para tanto? É sabido que quase nenhum daqueles direitos materiais é cumprido hodiernamente à risca. Ferdinand Lassale ${ }^{4}$ questionava com propriedade a essência da Constituição quando introduziu a soma dos "fatores reais de poder" que regem uma nação, afirmando que sem a presença dos mesmos uma Constituição não teria força, e simplesmente não passaria de uma "folha de papel escrita". A fim de estimular tal debate acadêmico, Konrad Hesse traz à tona a teoria da "força normativa", resgatando tal discussão sobre essa mesma Lei Maior onde a essência de uma Constituição encontrava-se em sua força normativa, ou seja, em seus aspectos jurídicos relacionados com a realidade sócio-política de um Estado ${ }^{5}$.

No entanto, saindo desse confronto histórico e teórico e chegando no tempo presente, como resgatar essa discussão travada entre os séculos

2 Notoriamente reconhecidas como revoluções agrária, industrial e da informação.

3 Art. $6^{\circ}$ São direitos sociais a educação, a saúde, a alimentação, o trabalho, a moradia, o lazer, a segurança, a previdência social, a proteção à maternidade e à infância, a assistência aos desamparados, na forma desta Constituição.

(...)

Art. 205. A educação, direito de todos e dever do Estado e da família, será promovida e incentivada com a colaboração da sociedade, visando ao pleno desenvolvimento da pessoa, seu preparo para o exercício da cidadania e sua qualificação para o trabalho.

4 "Tenho demonstrado a relação que guardam entre si as duas constituições de um país: essa constituição real e efetiva, integralizada pelos fatores reais de poder que regem a sociedade, e essa outra constituição escrita, à qual, para distingui-Ia da primeira, vamos denominar folha de papel (alusão à célebre frase de Frederico Guilherme IV, que disse: 'Julgo-me obrigado a fazer agora, solenemente, a declaração de que nem no presente nem para o futuro permitirei que entre Deus do céu e o meu país se interponha uma folha de papel escrita como se fosse uma segunda Providência. ')" Cf. LASSALE, F. (2009). A Essência da Constituição$9^{\text {a }}$. edição. Editora Lumen Iuris, Rio de Janeiro.

5 "A constituição converte-se à em força ativa se fizerem-se presentes, na consciência dos principais responsáveis pela ordem constitucionais, não só a vontade de poder, mas também a vontade de constituição”. Cf. HESSE, K. (1991). A Força Normativa da Constituição. Porto alegre, Ed. Sergio Antonio Fabris. p.19. 
XVIII e XIX por aquele político e pelo outro magistrado, respectivamente? Será que nessa mesma linha de raciocínio lógico seria premente tornar o acesso à internet como um direito fundamental? $\mathrm{Ou}$ seguindo Hesse devemos buscar essa força normativa (direito fundamental e dever do Estado e da família, respectivamente nos artigos $6^{\circ} \mathrm{e} 205^{\circ} \mathrm{da} \mathrm{CF} / 88$ ) proposta pelo jurista alemão para que não incorramos no pensamento de Lassale e redundamos numa mera folha de papel, já doutrinada algum tempo atrás.

Em tempos modernos, como se daria hoje o uso de computadores, do acesso dos cidadãos ao uso da internet, (independente de sua tecnologia), seja banda larga, fibra óptica, wireless ou afins? Como fazer para se tornar algo possível? Seria destinado a que público alvo? Com que recursos e ferramentas técnicas para se tornar uma realidade? Existiria a necessidade de algum conhecimento básico para o seu manuseio? Que tipo de conteúdo se poderia ter acesso, isso seria relevante? Já existe algum projeto de lei ou PEC nesse sentido? São várias indagações que o presente estudo tem a intenção de tentar buscar uma resposta para as mesmas. Todavia é sabido que o conhecimento é infinito e mutável, como são os fenômenos sociais que são imprevisíveis a qualquer ser vivo. Para uma melhor compreensão do tema, analisaremos os vocábulos "educação" e "tecnologia" a fim de se vislumbrar a relevância e possibilidade de união dos mesmos na era da informação.

\section{EDUCAÇÃO E TECNOLOGIA UMA UNIÃO POSSÍVEL?}

É sabido que ao longo da história, o acesso ao conhecimento sempre foi difícil e às vezes de escassa oferta. Com a criação da escrita e proliferação dos textos, somente uma pequena parcela da sociedade tinha acesso ao tal desejável conhecimento. Conforme afirma Juan Carlos Tedesco (2003) desde o começo do século XIX os níveis de analfabetismo eram extraordinários no mundo (p.24). Como dito no capítulo anterior, com o advento da imprensa, tal revolução se concretizou, ao ficar a escrita registrada em textos que poderiam ser reproduzidos facilmente, facilitando sobremaneira a disseminação do conhecimento, como ocorrera na afamada Universidade Harvard que levou 275 anos para reunir seu primeiro milhão de livros, e reuniu o último milhão em apenas cinco anos.

Pierre Levy (2010), filósofo da informação e visionário contemporâneo afirmou que: 
As relações entre os homens, o trabalho, a própria inteligência dependem, na verdade, da metamorfose incessante de dispositivos informacionais de todos os tipos. Escrita, leitura, visão, audição, criação, aprendizagem são capturados por uma informática cada vez mais avançada. Não se pode mais conceber a pesquisa científica sem uma aparelhagem complexa que redistribui as antigas divisões entre experiência e teoria. Emerge, neste final do século XX, um conhecimento por simulação que os epistemologistas ainda não inventariam. (p.5-6).

Hodiernamente, com a internet é muito mais fácil acessar qualquer tipo de conteúdo, ilimitadamente sem a preocupação em transpor as barreiras do tamanho, tempo e do espaço ${ }^{6}$. Só para termos uma noção de dados estatísticos disponíveis e que trafegam na internet, Tedesco (2003) vislumbrou tal abundância de informações na World Wide Web, notadamente, conhecida como rede mundial de computadores

Como antecipou em certo momento a diretora educacional da ATT, esperava-se que em 2002 existissem oito bilhões de páginas eletrônicas na WWW, tendo-se calculado que, em meados do ano 2000, seu montante total - soma de páginas de superfície - alcançaria 2,5 bilhões, com uma taxa de crescimento diário de 7,3 milhões de páginas. Caso se considere, em contrapartida, a totalidade da informação acessível por meio da Rede, incluindo base de dados conectadas, páginas dinâmicas, sites da Internet (conhecidos como a Rede "profunda"), estima-se que, nessa mesma data, a rede reunia 550 bilhões de páginas ou documentos, $95 \%$ dos quais eram publicamente acessíveis. Por sua vez, o número de pessoas que acessam a internet - embora ainda seja uma minoria no mundo, altamente concentrada nos países do Norte - aumenta em um ritmo constante, estimando-se que poderia chegar a um bilhão nos próximos dezanos. (p.24).

6 Remetemos a outro trabalho anterior que discute tal foco, Cf. TOMIZAWA, Op. cit. 17.

7 “De acordo com a Internet World Stats, 1,96 bilhão de pessoas tinham acesso à Internet em junho de 2010, o que representa $28,7 \%$ da população mundial. Segundo a pesquisa, a Europa detinha quase 420 milhões de usuários, mais da metade da população. Mais de $60 \%$ da população da Oceania tem o acesso à Internet, mas esse percentual é reduzido para 6,8\% na África. Na América Latina e Caribe, um pouco mais de 200 milhões de pessoas têm acesso à Internet (de acordo com dados de junho de 2010), sendo que quase 76 milhões são brasileiros". Cf. WIKIPEDIA. (n.d). Disponível em: $<$ http://pt.wikipedia.org/wiki/Internet $>$ 
Ao momento de compormos tal artigo, chegamos à essa realidade virtual $^{7}$. Não queremos de forma alguma trazer tal pesquisa a fim de mostrar a ineficiência do usas tecnologias como bem ressaltado por Pierre Levy (2010).

Não se trata aqui, portanto, de profetizar uma catástrofe cultural causada pela informatização, mas sim de utilizar os trabalhos recentes da psicologia cognitiva e da história dos processos de inserção para analisar precisamente a articulação entre gêneros de conhecimento e tecnologias intelectuais. (p.5-6).

O que se reflexiona, ademais, é demonstrar se a informação é destinada apenas à uma parcela da população. Somente as classes dominantes e abastadas ou que tivessem acesso à tais recursos tecnológicos poderiam alcançar à uma vital informação e/ou conhecimento específico e por conseqüência disso, à uma melhor educação de base e uma melhor inserção no mercado de trabalho, por exemplo? Estamos falando de uma verdadeira inclusão digital ${ }^{8}$ que vai de encontro ao analfabetismo digital $^{9}$, ou se preferir aos excluídos digitalmente. Patricia Scorzelli (1997) ao analisar a era digital em seu livro faz um comentário oportuno para esclarecer a iminente preocupação que aflige os sociólogos e estudiosos em geral

Depois de milênios, chega-se então a Era da Informática; porém, depara-se, de certa maneira, com um problema que acompanha toda a história da comunicação, ou seja, desde a

\footnotetext{
8 "Compreendida de maneira mais ampla do que o simples acesso ao computador, a Inclusão Digital é um conceito que engloba as novas tecnologias da informação e comunicação, a educação, o protagonismo, possibilitando a construção de uma cidadania criativa e empreendedora. A Inclusão Digital é um meio para promover a melhoria da qualidade de vida, garantir maior liberdade social, gerar conhecimento e troca de informações. Temos, então o surgimento do excluído digital, o marginalizado do século XXI". Cf. MALAQUIAS, B. P. (2012). O Analfabetismo Digital. Instituto Brasileiro de Direito e Informática. Disponível em: $<$ http://www.ibdi.org.br/site/artigos.php?id=159>

9 “(...) aquele que não domina a informática é um verdadeiro analfabeto, marginalizado pela rápida evolução tecnológica que possibilita o acesso à informação. O analfabetismo digital é um grande fator de exclusão, que resulta em sérias implicações sociais, políticas, jurídicas e econômicas. Antes se falava que aquele que não fosse devidamente alfabetizado, que não conseguisse interpretar e compreender um texto, estava marginalizado, estigmatizado. Com esteio nesta assertiva, essa tal pessoa não teria sua cidadania exercida plenamente, estando, pois, fadada inexoravelmente a um destino sem perspectivas, restando-lhe somente subempregos. Com efeito, a exclusão agora é outra. Hoje, "navegar" é imprescindível, sobretudo, dominar as tecnologias de informação. Sem embargos, informação é poder. Diante de tais circunstâncias, o já estreito funil da exclusão ficou mais apertado. É de incontroverso saber que a Internet e o computador são ferramentas imprescindíveis para quem quer se inserir no mercado de trabalho. Isto porque, desde o balconista do supermercado até o dentista ou o advogado, a todos se impõe o uso da informática. Qualquer profissional precisa dominar as tecnologias de informação, seja ele quem for, esteja ele onde estiver. Hodiernamente, sem informação não há comunicação, o que resulta em exclusão, marginalização". MALAQUIAS, B. P. (2012).
} 
era dos sumérios e dos egípcios: as inovações tecnológicas levam um tempo considerável para atingir as classes menos favorecidas, sempre alijadas dos processos de renovação $e$ de seus beneficios.

Será que a falta de computador tende a criar uma nova forma de analfabetismo? (p.12).

A educação é a base de tudo em qualquer lugar ou momento histórico, é notoriamente sabido que os países ${ }^{10}$ que investem e investiram em Educação tem muito mais possibilidade de se despontarem como países emergentes e se tornarem potências mundiais em todos os níveis de desenvolvimento do homem. Gardner (1999) aprofunda a indagação

Conseqüentemente, o problema para a educação na atualidade não é onde encontrar a informação, mas como oferecer acesso a ela sem exclusões e, ao mesmo tempo, aprender e ensinar a selecioná-la, avaliá-la, interpretá-la, classificá-la e usá-la. Há uma questão adicional envolvida aqui: como desenvolver as funções cognitivas superiores funções de 'problem-solving, problem-finding, planning, reflectings, creativity, deeper understanding' indispensáveis num meio saturado de informação, evitando assim que o ensino fique reduzido ao nível de destrezas elementares. Assim, também, a escola deixa de ser o principal meio de informação para as novas gerações e deve concorrer com outros meios, como a televisão e a Internet, da qual se espera, ademais, que ela informe e ensine. (p.75).

Hoje se fala que o ser humano não sabe mais distinguir informação boa da ruim, da essencial da supérflua, da bisbilhotice e da fofoca, da informação necessária e relevante à sociedade. Como as crianças e jovens se valiam para obter um conhecimento geral, específico e/ou acesso à informação antes da chegada da internet e dos mecanismos de busca, tais como o Google e afins? Hoje criou-se a verdadeira era "pósgoogle", geração de adolescentes que pouco sabem, não se interessam e nem se esforçariam para obter a fonte real de livros e bibliotecas, como

10 Essa realidade ocorre em países tais como Reino Unido, Malásia, Finlândia, Irlanda, Espanha e Coréia do Sul (ver CUNHA C. da \& WERTHEIN J. (2004). Educação e Conhecimento: a experiência dos que avançaram, Ministério da Educação, Brasília: UNESCO), para saber mais sobre esse último ler a matéria de WEINBERG, M. (2012). 7 lições da Coréia para o Brasil: O que o país pode aprender com o bem-sucedido modelo de educação implantado na Coréia do Sul. VEJA on-line. Disponível em: $<$ http://veja.abril.com.br/ $160205 / \mathrm{p}$ 060.html>

11 Tal tema foi tratado por Paulo Serra do qual concordamos integralmente: "Deve-se ponderar a respeito do que realmente é informação necessária ou o que é excesso de informação ou conteúdo desnecessário a fim de 
era outrora. O conteúdo é mastigado, superficial e às vezes até inútil ${ }^{11}$. Com o surgimento de tais tecnologias e infra-estruturas de aporte tais como lan-houses e redes wireless, e.g. o uso da internet se difundiu de maneira avalassadora no globo terrestre. No entanto essa disseminação não se deu da forma que se esperava quando se comparava áreas rurais, das urbanas ou ainda do acesso público ao acesso privado, geralmente em domicílios ${ }^{12}$. Passaremos a seguir a comentar sobre o acesso à internet como uma possível efetivação desse direito fundamental no ordenamento pátrio.

\section{O ACESSO À INTERNET COMO UM DIREITO FUNDAMENTAL NO ORDENAMENTO PÁTRIO}

Inicialmente deve-se tratar da teoria dos direitos fundamentais, de modo ampassant, pois longe de ser a real intenção do estudo trabalhar tal tema que já é larga e notoriamente consolidado brilhantemente na Europa em países tais como Alemanha ${ }^{13}$, Portugal ${ }^{14}$, Itália ${ }^{15}$ e Espanha $^{16}$, nos Estados Unidos $^{17}$ e finalmente no Brasil ${ }^{18}$, cabendo ressaltar que nosso país, prima facie, não existe direitos absolutos e o princípio da Unidade da Constituição deve ser severamente respeitado, já que a priori, não existe supremacia entre os dispositivos constitucionais, pois são de mesmo peso e valor hierárquico, nem mesmo quando avocamos o princípio da dignidade da pessoa humana ${ }^{19}$, como é entendido no Tribunal

ser filtrado por nós". Ver GUIERA, A. T. \& TOMIZAWA, G. (2011). A evasão de privacidade e a inversão de valores na sociedade pós-industrial. In: ARAGÃO, P.; ROMANO, L. D.; TAYAH, J. M. (coord.). Reflexiones sobre Derecho Latino Americano - Estudios en homenaje al Profesor Eduardo Barbarosch. Vol. 5. Buenos Aires: Editorial Quorum. p. 242.

12 Na apresentação dos resultados da TIC domicílios de 2007, o CGI.br apontava que as lanhouses "se tornaram o local mais utilizado para o acesso à Internet no país, principalmente entre os jovens e indivíduos de baixa renda". (...) Entretanto, a pesquisa de 2008 apontou que as lanhouses, embora se mantenham como principal meio de acesso público, perdiam espaço na área urbana para o acesso à internet nos domicílios. Ressaltava-se, então, sua importância "na área rural" (na área rural, 58\% dos usuários informaram acessa a Internet nesses espaços e somente $26 \%$ informaram acessá-la de casa) onde os serviços de banda larga não estão adequados às necessidades dos brasileiros, seja por seu alto custo, seja pela indisponibilidade do serviço. Agora, a pesquisa de 2009 confirma essa perda de espaço da lanhouse para o domicílio, inclusive no interior, tanto no acesso à internet como no uso do computador. Cf. WAGNER, J. (2010). Pesquisa sobre o uso das tecnologias da informação e da comunicação no Brasil TIC Domicílios e TIC Empresas 2009: o pnbl e os pequenos provedores. CGI.BR (Comitê Gestor da Internet no Brasil), São Paulo. p. 81-82.

13 Robert Alexy (Theorie der Grundrechte), Peter Haberle, Konrad Hesse, Hans Kelsen, dentre outros.

14 José Joaquim Gomes Canotilho, José Carlos Vieira de Andrade, Jorge Miranda, Catarina Sarmento Castro, dentre outros.

15 Norberto Bobbio (A era dos direitos).

16 Antonio Enrique Perez Luño (Los derechos fundamentales).

17 Ronald Dworkin (Taking rights seriously)

18 Juristas do porte de Ingo Wolfgang Sarlet, Luis Roberto Barroso, Gilmar Ferreira Mendes, Daniel Sarmento, Humberto Ávila, dentre outros.

19 Art. $1^{\circ}$ A República Federativa do Brasil, formada pela união indissolúvel dos Estados e Municípios e do Distrito Federal, constitui-se em Estado Democrático de Direito e tem como fundamentos: (...) III - a dignidade da pessoa humana. 
Constitucional Federal Alemão (Deutsch Bundes verfassung groundrechte $)^{20}$. Pérez Lunõ (1984) trata bem a definição de direito fundamental

Um conjunto de facultades y instituciones que, em cada momento histórico, concretan las exigências de la dignidad, la libertad y la igualdad humanas, las cuales deben ser reconocidas positivamente por los ordenamientos jurídicos a nível nacional y internacional.

Antes de adentrarmos ponto nevrálgico do tema, deve-se de maneira brevíssima ressaltar os principais aspectos da primorosa teoria dos 4 status de Jellinek ${ }^{21}$, somente em 2 aspectos $^{22}$, que nos interessam no presente estudo, direitos como em sua dimensão social negativa (direitos de abstenção) e direito em sua dimensão social positiva ${ }^{23}$ (inclusão digital), notadamente na esfera do poder público, e não no privado (com relação aos particulares), já que mais a frente comentaremos de políticas públicas para sua real efetivação e concretização. Para elucidar essas dimensões sociais de direitos nos socorremos ao estudo do prof. Ivar Hartmann que desbravou tal tema com destreza e maestria a que lhe é de seu feitio

Assim, o direito fundamental de acesso à Internet tem sua eficácia na dimensão negativa naquilo que tange à obrigação de abstenção, aqui tratada sob o aspecto da vinculação do Estado, de supressão do acesso do indivíduo à Rede, de proibição da ação estatal que limite desproporcionalmente o acesso em si e a troca de informações no ciberespaço. (...) Aqui esse mandado de abstenção implica apenas em não restringir ou suprimir um acesso para o qual o indivíduo precisa necessariamente do poder público. (nosso grifo).

\footnotetext{
20 Teoria da hierarquização de princípios constitucionais oriunda do Tribunal Constitucional Federal Alemão.

21 "Um direito público subjetivo", isto é, um direito individual que vincula o Estado. Cf. JELLINEK, G. System der Subjektiven Öffentlichen Rechte 1919. (1994), apud GAVARA de C., J. C. Derechos Fundamentales y desarollo legislativo: La garantia del contenido esencial de los derechos fundamentales em la Ley Fundamental de Bonn. Madrid: Centro de Estudios Constitucionales, p. 233.

22 "Os direitos de defesa se relacionam com o status negativo porque colocam o indivíduo em posição de defesa contra as intromissões estatais na sua esfera de liberdade; Os direitos a prestação vinculam-se ao status positivo por conferirem ao indivíduo situação jurídica de sujeito de direitos perante o Estado que lhes deve uma atuação positiva". Cf. VIEIRA, T. M. (2007). O Direito à privacidade na sociedade da informação: efetividade desse direito fundamental diante dos avanços da tecnologia da informação. Sergio Antonio Fabris Editor, Porto Alegre. p. 84-95.
} 
O renomado prof. José Joaquim Gomes Canotilho (1993) também trata tal tema nessa mesma linha de raciocínio

a função de direitos de defesa do cidadão sob uma dupla perspectiva: (1) constituem, num plano jurídico-objectivo, normas de competência negativa para os poderes públicos, proibindo fundamentalmente as ingerências destes na esfera jurídica individual; (2) implicam, num plano jurídicosubjectivo, o poder de exercer positivamente direitos fundamentais (liberdade positiva) e de exigir omissões dos poderes públicos, de forma a evitar agressões lesivas por parte dos mesmos (liberdade negativa). (p. 541).

O que deve-se verificar na dimensão negativa é até quando o Estado poderia se fazer prevalecer seu poder de abstenção quando o assunto é o estado policialesco ${ }^{24}$ e de censura de internet ou do óbice de acesso à informações na rede, quando avocamos o direito à liberdade de expressão por exemplo, diante dos entes privados.

Dependendo do fator geográfico, político-histórico, existem governos autoritários a exemplo da Coréia do Norte, Irã, China, Cuba ou Arábia Saudita que monitoram a censura na internet, em aspectos políticos (onde a violação de direitos humanos, tais como a liberdade de expressão são uma constante), ou conflitos e segurança (no que tange à conflitos armados e movimentos separatistas), ferramentas de internet (redes

23 "Dependendo da matéria, o Estado pode ser obrigado a fazer algo (exemplo: garantir o acesso de todas as crianças às escolas) ou abster-se de atuar (exemplo: o policial não pode a princípio, ou seja, salvo exceções definidas por lei, adentrar o domicílio do indivíduo)". Cf. DIMOULIS, D. \& MARTINS, L. (2008). Teoria Geral dos Direitos Fundamentais. Editora RT, São Paulo, 2ª tiragem.p. 63.

24 Tal tema já foi objeto de estudo quando comentamos da intrusão do Estado diante das agências de inteligência e ferramentas de espionagem que controlam os internautas na rede. "(...) Depois dos atentados terroristas de 11 de setembro de 2001, a maioria dos governos de todo o mundo dera início, e alguns casos continuidade, a uma vigilância global sem precedentes utilizando, para tanto, a estrutura física da Internet e em alguns casos edições de leis mesmo que muitas vezes violadoras de nossas garantias fundamentais. O que ocorre é que há muito tempo atrás, alguns governos já estão realizando atos de espionagem em grande escala na internet. Alguns deles se desenvolveram dentro da própria Rede, outros, no entanto, não foram criados com esse fim. Certamente devem existir outros países que desenvolveram sistemas e programas de vigilância em escala mundial, porém costumeiramente negam a sua existência a fim de não ferir diretos constitucionais de seus cidadãos. Contemporaneamente os países que possuem sistemas de vigilâncias eletrônicas admitem (e quando admitem) o funcionamento com base no combate a proliferação do terrorismo e outras condutas ilícitas que se espalham com o uso dessa nova ferramenta de tecnologia que é a rede mundial de computadores. Esses mesmos governos se respaldam na justificativa de garantir a ordem e a segurança pública da sociedade, seja ela virtual ou não. Por mais justificável que seja tal argumento, tais sistemas de vigilância eletrônica violam a privacidade e a intimidade dos internautas dentro da Rede ou fora dela". Cf. TOMIZAWA, G. (2012). O Direito à privacidade e a intromissão estatal através dos sistemas de inteligência e ferramentas de espionagem dentro da Internet. ANIMA V - Revista de Direito Eletrônico do Curso de Direito da OPET. ISSN 2175-7119, Volume 5, série 5, págs. 302-316. Disponível em: http://www.animaopet.com.br/pdf/anima5-Professores/GUILHERME-TOMIZAWA-ANIMA5.pdf 
sociais e blogs de discussão) onde os membros dessas sociedades podem ser previamente julgados pelo conteúdo que disponibilizam (ofensivos à moral, como sexo e jogos de azar) na rede mundial de computadores. Os poucos sites aprovados na Coréia do Norte passam pelo crivo do governo. No Irã o a velocidade máxima de conexão à rede é de $128 \mathrm{Kbps}$, dificultando (propositalmente) o acesso à vídeos. Na China além de existir o bloqueio de sites com críticas ao governo, a freqüente prisão de blogueiros inibe a livre expressão na rede. Em Cuba, todos os e-mails com palavras que indiquem algo suspeito tais como "dissidência política" são automaticamente interceptados. E por fim, na Arábia Saudita, são censurados os conteúdos de ordem imoral (classificados por esse governo) à exemplo de pornografia e educação sexual (Camila Pereira \& Renata Betti, 2009).

Sendo assim, como já ressaltamos anteriormente e reiterado por Hartmann (2010).

Embora não seja o caso no Brasil, há sim Estados que fazem do desrespeito a essa obrigação de abstenção praticamente um remendo que garante a sustentação de seu modo autoritário de atuação. Um direito fundamental de acesso à Internet tem por dimensão negativa exatamente a obrigação do Estado de não realizar medidas restritivas da livre atuação da pessoa no ciberespaço, atuação esta tanto como emissor quanto como receptor de informações as mais diversas ( $p$. 163-164).

Todavia a ideia é avançarmos na discussão no que tange a dimensão social positiva do Estado. $\mathrm{O}$ acesso à internet como direito fundamental social, mas conhecido como fenômeno da "inclusão digital". Pode até soar exagerado estarmos tratando especificamente do acesso a ferramenta da internet como um direito fundamental, quando vemos tantos outros direitos básicos ${ }^{25}$ sendo relegados ao esquecimento ou que simplesmente são vilipendiados dia a dia em nosso país. É difícil para um país como o Brasil, "sem" o acesso à informação na rede mundial de computadores ser considerado excluído ou marginalizado socialmente diante de tanta pobreza e injustiças latentes em nossa nação. Porém, como já tratado antes, vivemos uma verdadeira "sociedade-rede" onde a promoção para uma qualidade de vida está sim umbilicalmente ligado ao uso da internet.

É mister acompanhar o raciocínio da seguinte forma: se uma pessoa com 25 Aqui podemos citar dentre esses direitos: vida, alimentação, saúde, educação, propriedade, segurança, lazer, ofício, dentre tantos outros. 
poucos recursos, conscientizada, com vontade de se superar que pode se tornar alguém muito melhor para si como para sociedade, tiver hipoteticamente um maior acesso à informação que trafega na rede ou à um conteúdo específico e essencial para o seu desenvolvimento, com toda certeza tal indivíduo terá uma melhor formação e educação direcionada. Por conseqüência disso terá um currículo mais avantajado daquele que não tem, conquistando uma melhor colocação no mercado de trabalho e transformando em um cidadão mais criativo e empreendedor, ganhando respeito próprio e segurança que sobremaneira suprirá indiretamente ou até diretamente os outros direitos fundamentais (saúde, lazer, segurança, etc.) supra comentados, e estatuídos pela Carta Magna Brasileira. Estaremos tratando aqui de verdadeiros analfabetos digitais, indivíduos como bem disse Bruno Pires ${ }^{26}$ que só lhe restarão subempregos diante dessa marginalização que nem imaginam que se enquadram estaticamente ${ }^{27}$ em nosso país, onde não passam de números estigmatizados, meios cidadãos sem perspectivas, fadados à uma verdadeira exclusão social e porque não digital ${ }^{28}$.

Manuel Castells (2006), sociólogo espanhol, especialista em comunicação, marco teórico em estudos da internet alertou

É essencial perceber que a exclusão digital aqui funciona como um fator acumulativo, pois quanto mais tempo demorar para que certas pessoas e faixas de população sejam incluídas, maior será a desvantagem profissional dessas em relação àquelas privilegiadas, estimulando ainda mais a desigualdade social e concentração de renda. (p. 439) (grifo nosso).

Tal tema que envolve os conflitos entre classes dominantes/dominadas, espoliadas e espoliadores, é bastante abordado pela dupla de estudiosos críticos contemporâneos do porte de Roberto Lyra Filho (1995) e Luis Fernando Coelho (2004).

Logicamente para se concretizar tal realidade e tornar algo palpável deve-se

(...) comprar um computador pessoal, de alto custo - aquele

\footnotetext{
26 Ver citações n ${ }^{\circ} 15$ e 16 do presente ensaio acadêmico.

27 "De acordo com o Mapa da Exclusão Digital, que analisou os dados do Censo 2000, o nível de escolaridade é ponto de importância não só na geração de renda, mas também no nível de inclusão digital dos estados brasileiros: os cinco mais incluídos são o Distrito Federal, São Paulo, Rio de Janeiro, Santa Catarina e Paraná, e os cinco mais excluídos são o Maranhão, Piauí, Tocantins, Acre e Alagoas”. Cf. WIKIPEDIA. (n.d). Disponível em: $<$ http://pt.wikipedia.org/wiki/Exclus\%C3\%A3o_digital $>$

28 Termo denominado pelos norte-americanos como digital divide e pelos franceses de fracture numérique.
} 
que deseja conectar-se necessita ainda arcar com uma mensalidade referente à transmissão de dados, seja por meio telefônico, como inicialmente seja via cabo, rádio ou satélite. Esse é um obstáculo que já diferencia a Internet de meios de comunicação como o rádio e a televisão, implicando uma capacidade de penetração social muito maior para os dois últimos. É claro que os custos para aquele que são os primeiros a adotarem uma tecnologia ou novidade sempre são maiores que para os demais, que aderem apenas mais tarde. Com a popularização, tanto os computadores quanto os serviços fornecidos pelos provedores de acesso tornaramse mais baratos e acessíveis também para a classe média e média baixa (Hartmann, 2010).

Hartmann ainda ressalta que a adoção de novas tecnologias pelas camadas menos abastadas é muito mais morosa, com certeza, devendo inclusive levar em consideração a classe de pessoas que não estão nem interessadas em acessar à internet ${ }^{29}$. Mesmo de forma hipotética fosse superado tal impasse de ordem econômica, estaríamos ainda esbarrando em outro vértice do problema, que seria o nível de capacidade intelectual para acessar a Internet de forma concreta e participar eficazmente desse inexorável processo sem volta ${ }^{30}$.

Outrossim, não poderíamos adotar medidas paliativas e insensatas de custear um curso de capacitação à toda sociedade desprivilegiada de conhecimento para operar um computador. Inicialmente precisa-se de um plano de custeio à longo prazo a fim de analisar cuidadosamente a relação custo-benefício para tal desiderato. Por isso que o direito à educação com vistas à uma melhor condição de trabalho é uma preocupação premente que se fez clara desde o capítulo 2 do presente estudo. Por isso nesse viés que concordamos inequivocadamente com Hartmann que

(...) o direito fundamental ao acesso à Internet constitui um direito fundamental social na sociedade-rede. Direito Social

29 COMPAINE, B. M. (2001). Declare the war won. In: COMPAINE, B. M. (org.). The digital divide: facing a crisis or creating a myth? Cambridge (MA): MIT. p. 328. "As pessoas com esse perfil geralmente são aquelas com maior dificuldade para utilizar novas tecnologias, como idosos. Ademais, o número daqueles que sabem e podem acessar a Rede, mas não vêem motivo para fazê-lo, diminuirá largamente em uma sociedade-rede".

30 Hartmann chama atenção para esse tópico em especial já que para ele "o potencial de alcance e velocidade de penetração da Internet, mostra-se muito menor que o da televisão, do rádio e do telefone e, inclusive, da imprensa escrita. Não é necessário qualquer preparo ou conhecimento diversificado para usar um telefone ou assistir uma novela. Mesmo a leitura de um jornal requer habilidades que são dominadas por um número maior de pessoas que as habilidades necessárias para a participação adequada na Internet. Têm-se referido ao problema como a information literacy". Cf. HARTAMNN, Op. cit. p. 167. 
justamente porque, assim como o direito à educação e o direito à saúde, visa a garantir as condições mínimas para uma existência digna e para a convivência da pessoa em sociedade (Hartmann, 2010).

Como já muito bem delineado pelo prof. Ivar Alberto Martins Hartmann o uso da internet pode trazer inúmeros benefícios ao homem comum ou mediano quando tem acesso à essa ferramenta com status de direito fundamental que sobremaneira iriam ser um benefício sem precedentes às classes menos abastadas ou excluídas "digitalmente"

Podem-se citar diversos aspectos da concretização de direitos sociais diretamente afetados pela popularização do uso da Internet e outras TI, entre eles: capacidades na área de TI aumentam a possibilidade de colocação no mercado de trabalho; as TI podem contribuir significativamente para a aquisição de habilidades (sejam elas relacionadas às TI ou não); TI podem aprimorar significativamente o acesso a, e o resultado de, a educação e o treinamento técnico; TI podem ser utilizadas para prover acesso a mercados de trabalho de outra forma inacessíveis; TI podem ser usadas para incrementar a habilidade das pessoas para aproveitarem-se de serviços públicos sociais; TI têm o potencial de aprimorar o acesso ao sistema público de saúde; TI podem ser usadas para sustentar redes sociais e construir comunidades (nesse aspecto, conforme desenvolvido a fundo no segundo capitulo). Ademais, há uma profunda ligação a ser percebida também entre a inclusão digital e a coesão social - aqui uma perspectiva não individual, mas sim coletiva da realização de direitos sociais, centrada no grau de interconectividade em redes sociais. A coesão social, nesse contexto, envolve os conceitos de participação e capacidade (econômica, física, social, etc.) e a oportunidade para tanto. (2010, p. 169).

Atualmente tramita no Congresso $\mathrm{Nacional}^{31}$ a possibilidade desse

31 “Apesar de registrar avanços em suas redes de telecomunicações, o Brasil ocupava, em 2008, a 69a posição entre 193 países com acesso à internet listados pela UIT (União Internacional de Telecomunicações). Bem atrás de países como Austrália, Holanda, Suécia e Islândia, onde 70\% a 90\% da população se conectam à rede mundial de computadores, o Brasil - com apenas 17,2\% de sua população, à época, inserida no mundo virtual - também perdia posição em relação aos vizinhos Argentina (17,8\%), Uruguai (20,6\%) e Chile (28,9\%) (...)A advertência encontrou respaldo no estudo Lápis, Borracha e Teclado, realizado pelo pesquisador Julio Jacobo Waiselfisz em 2007. O levantamento apurou que, entre os $10 \%$ mais pobres, apenas $0,6 \%$ tinham acesso a computador com internet, índice que alcançava $56,3 \%$ entre os $10 \%$ mais ricos. Na análise por raça, constatou que apenas $13,3 \%$ dos negros usavam a internet, realidade presente entre $28,3 \%$ dos brasileiros brancos. As disparidades regionais também se reproduzem nessa área. Enquanto o índice de acesso à rede mundial de 
direito (acesso à internet) se tornar uma realidade através da $\mathrm{PEC} \mathrm{n}^{\circ}$ 6/11 em tramitação na CCJ (Comissão de Constituição, Justiça e Cidadania). $\mathrm{O}$ mentor desse projeto, deputado Rodrigo Rollemberg expõe suas razões para a edição de tal emenda

O desfrute de muitos direitos do cidadão, como o da informação, o da educação, o do trabalho e o da remuneração digna, depende cada vez mais do acesso às novas tecnologias de informação e comunicação. Daí a necessidade de incluir tal acesso como um direito constitucional ${ }^{32}$.

Em paralelo com a PEC retrocitada existe ainda outra PEC n ${ }^{\circ} 479 / 2010$ que trata do acesso à internet de "banda larga",33. Tais propostas de emenda à constituição, como já afirmado outrora, são um caminho sem volta, demonstram a urgência e a necessidade patente dos "excluídos" digitalmente conforme pesquisas que ressaltam a importância de medidas para garantir direitos subjetivos individuais sejam concretizados através de direitos fundamentais de "prestação", aqui leiase um direito social, como norma auto-aplicável ou auto-executável ${ }^{34}$, que restará às instituições políticas tradicionais de garantirem e apresentarem tais clamores da sociedade marginalizada embasados em pesquisas científicas fidedignas oriundas de profissionais e técnicos capacitados, muita vontade política e execução de políticas públicas razoáveis e possíveis de se concretizarem, a fim de sanar tais deficiências em que o Estado não consegue eficazmente cumprir o verdadeiro papel de um Estado Democrático de Direito.

\footnotetext{
computadores chegava a 26,6\% no Sul, limitava-se a $11,9 \%$ no Nordeste. O estudo citado mostrou ainda assinala Rollemberg - profundas desigualdades no ambiente escolar. Revelou, por exemplo, uma distância expressiva na inclusão digital entre alunos do ensino médio público $(37,3 \%)$ e privado $(83,6 \%)$. O parlamentar teme que esse cenário possa comprometer o futuro do país ao reduzir as oportunidades educacionais, sociais e profissionais dos brasileiros vitimados por esse 'apartheid digital' ". Cf. PEC inclui acesso à internet como direito social na Constituição (n.d). . Disponível em: $<$ http://ultimainstancia.uol.com.br/conteudo/noticias/50580/pec+inclui+acesso $+\mathrm{a}+$ internet + como + direito + social+na+constituicao.shtml>

32 Loc. cit.

33 Câmara Federal. (n.d). CCJ aprova admissibilidade de PEC sobre acesso a internet de banda larga: a proposta inclui o acesso a internet de alta velocidade entre os direitos fundamentais do cidadão na Constituição. Disponível em: http://www2.camara.gov.br/agencia/noticias/COMUNICACAO/197765-CCJ APROVA-ADMISSIBILIDADE-DE-PEC-SOBRE-ACESSO-A-INTERNEFDE-BANDA-LARGA.html 34 A doutrina clássica norte-americana (embasada no trabalho de Thomas Colley) introduziu no Brasil por meio de Rui Barbosa as normas constitucionais do ponto de vista de sua aplicabilidade em self executing provisions (auto aplicáveis ou auto-executáveis) e not self executing provisions (não-auto-aplicáveis ou não auto-executáveis). Cf. SILVA, José Afonso da. Aplicabilidade das normas constitucionais. 33. Ed. São Paulo: Malheiros, 1998. "Tendo em conta, igualmente, a sua eficácia e aplicabilidade, consideram-se auto-executáveis as disposições constitucionais bastantes em si, completas e suficientemente precisas na sua hipótese de incidência e na sua disposição, aquelas que ministram os meios pelos quais se possa exercer ou proteger o direito que conferem, ou cumprir o dever e desempenhar o encargo que elas impõe"; Cf. MENDES, G. F. \& COELHO, I. M. \& BRANCO, P. G. G. (2008). Curso de Direito Constitucional. Editora Saraiva, 2a . edição revista e atualizada. São Paulo. p. 28.
} 
Por último, passaremos a tratar de alguns exemplos de políticas públicas de inclusão digital, na sua dimensão social positiva, em algumas localidades em especial, para verificarmos se se trata de uma realidade material ou de uma ficção jurídica ou um mero ideal platônico.

\section{TELECENTROS - POLÍTICAS PÚBLICAS DE INCLUSÃO DIGITAL, UMA POSSIBILIDADE MATERIAL?}

Diversas políticas públicas ${ }^{35}$ de inclusão digital têm sido desenvolvidas pelo governo brasileiro e que tem verdadeiramente funcionado em algumas cidades ${ }^{36}$ (inclusive digitais $^{37}$ ) e Estados do nosso país.

Outro exemplo magistral de políticas públicas são os denominados "Telecentros" ${ }^{38}$ que possuem outros sinônimos" ${ }^{39}$, são espaços públicos onde os cidadãos podem através do uso de computadores, terem acesso ilimitado à internet permitindo o que o mesmo possa interagir com dados e informações disponibilizadas na rede mundial de computadores, se comunicando com outras pessoas em qualquer lugar do mundo,

35 Wi-fi (é uma das tecnologias mais utilizadas atualmente para complementar uma infraestrutura de Cidade Digital, oferecendo acesso à internet em alta velocidade, sem fio, a quem esteja usando equipamentos móveis e no raio de ação de um ponto de acesso, conhecido como hotspot, ponto-a ponto (a ponto a ponto interliga as estações radiobase entre si, permitindo a instalação de várias delas dentro de uma cidade, inclusive em áreas remotas), ponto-multiponto (é utilizada para chegar na ponta, ou seja, na localidade que precisa de conexão sem fio, como escolas, postos de saúde, faz a distribuição do sinal a partir de um ponto central e "ilumina" prédios e outras áreas públicas, sendo também usada para interconectar redes Mesh), WiMAX (proporciona conectividade em banda larga sem fio de alcance mais longo que o Wi-fi, com a vantagem de não precisar de linha de visada direta à estação radiobase para ter ótimo desempenho, e Mesh (ou redes em malha, aplicam às redes sem fio a mesma arquitetura de roteamento distribuído encontrada na internet. É formada quando uma série de roteadores sem fio (repetidores) é conectada a nós ou pontos de acesso inteligentes para fornecer cobertura sobre uma área maior do que a possibilitada com um ponto de acesso independente, ou hotspot. Cf. DIGITAIS, Guia das Cidades (n.d). Um leque de possibilidades. Março de 2009. Disponível em: <www.guiadascidadesigitais.com.br>

36 No Estado do Pará, 15 cidades (Abaetetuba, Altamira, Barcarena, Belém, Belém, Itaituba, Jacundá, Marabá, Marituba, Pacajá, Rurópolis, Santa Maria, Santarém, Tailândia, Tucuruí e Uruará) foram incluídas na primeira fase do projeto Cidades Digitais (ver próxima nota).

37 "Quando se fala em Cidade Digital, pensa-se imediatamente em oferecer acesso à tecnologia às pessoas de classes sociais menos favorecidas. É isto? Também. Mas é muito mais. Significa criar um ambiente digital que favoreça a modernização da gestão pública, o empreendedorismo e o desenvolvimento econômico, além da prestação de serviços aos cidadãos em diversas áreas. Mas significa, principalmente, criar uma nova perspectiva de cidadania por meio da inclusão digital.” DIGITAIS, Guia das Cidades. Op. cit. p.2.

38 "Os Telecentros, muitas vezes também chamados de Infocentros, são locais de acesso à internet e de utilização de outros recursos de informática. Abertos a uma comunidade local, oferecem cursos, e principalmente, uso livre dos equipamentos por um tempo determinado, em geral com orientadores para possíveis auxílios ao usuário. São espaços de uso coletivo e, dependendo do grau de apropriação pela comunidade, podem inclusive abrigar projetos coletivos desenvolvidos a partir das TICS. Assim, a utilização do espaço relaciona-se com serviços, lazer, capacitação profissional, educação, política, saúde, produção cultural, comunicação e demais áreas, já que consiste em uma ferramenta de acesso e de produção de informação e conhecimento. A manutenção do espaço e dos equipamentos pode estar a cargo de um projeto público ou privado, ou mesmo da própria comunidade". Cf. BRASIL. (n.d). 4 CMBr Municípios Brasileiros: colaboração, comunidade, conhecimento e compartilhamento. O que é um telecentro?. Disponível em: $<$ http://www.softwarepublico.gov.br/4cmbr/xowiki/o_que_e_telecentro>

39 Os telecentros (normalmente ONGs, sem fins lucrativos) são conhecidos também por infocentros, vilas do conhecimento, centros comunitários de tecnologia ou de multimídia, telecentros escolares ou telecentros multifuncionais da comunidade. 
desenvolvendo habilidades digitais. Os telecentros tem a principal função de socializar o uso da internet em centros comunitários, primando pelo desenvolvimento econômico sustentável, aperfeiçoando políticas educacionais e sociais, visando o interesse comum da sociedade, democratizando o uso da ferramenta tecnológica com vistas a tornar o "princípio isonômico" uma realidade material e não somente uma ficção jurídica, uma igualdade "formal" que a doutrina e as faculdades apregoam aos quatros cantos do mundo.

Essa possibilidade de ter um acesso gratuito da internet já fora comentando por outros autores ${ }^{40}$, o qual é denominado de "Telecentro" que foi bem delineado outrora por Marcos Mazoni (2009) sobre tal realidade no nosso país

A União vem disponibilizando pontos de acesso, telecentros. Alguns projetos são mais audaciosos, como o Casa Brasil projeto interministerial cuja gestão é coordenada pela Casa Civil - e os Pontos de Cultura, desenvolvidos pelo Ministério da Cultura. Mas eles precisam estar articulados com as situações quê são diferenciadas localmente. E só quem lida com isso é o município: a questão local se estabelece através deles.

Todavia existem alguns desafios para que tais telecentros se tornem realidade, algo verdadeiramente "material". Precisa-se seriamente (de vontade política) para que tais "políticas públicas" sejam de fato concretizadas, que tais elementos de inclusão digital sejam devidamente seguidos e implementados,

O primeiro concerne à infraestrutura física: o edifício onde será instalado o telecentro, os equipamentos utilizados pelos indivíduos e o meio de acesso à Rede, se linha telefônica ou cabo, rádio, satélite, etc. No caso de comunidades geograficamente isoladas, o uso do acesso por satélite mostra-se de melhor custo-benefício.

O segundo elemento é a capacitação. É essencial a presença de professores e técnicos relacionados à área de informática para o treinamento contínuo da população que faz uso do telecentro, consubstanciando aspecto nuclear da inclusão

40 Tema já exaustivamente trabalhado por Ivar Alberto Martins Hartmann em 2 oportunidades em HARTMANN, Op. cit. e HARTMANN, I. A. M. (2008). O acesso à internet como direito fundamental. Revista de Derecho Informático, n. 118, maio 2008. Disponível em: http://www.alfa-redi.org/rdiarticulo.shtml? $\mathrm{x}=10359$ 
digital exatamente a "alfabetização digital", o provimento das habilidades necessárias para participar com sucesso do ciberespaço. Exemplo delas é o uso produtivo de um motor de busca como o Google.

O terceiro elemento é a gestão e custeio do telecentro, sua sustentabilidade. (...)

O quarto e último elemento é o conteúdo. De nada adianta fornecer o equipamento e a capacitação necessária para que um jovem no meio da Amazônia possa navegar no site de notícias do New York Times, em inglês. (...) Deve ser garantido conteúdo com o qual essa pessoa tem alguma relação, como notícias de sua própria região, ou o estabelecimento de uma rede de contatos com comunidades próximas ou mesmo no âmbito da vizinhança. Da mesma forma deve ser estimulada a produção de conteúdo pela comunidade e para a comunidade, fazendo de cada indivíduo um informador e não mero receptor. Aqui remetemo-nos às considerações de processos de inserção no ciberespaço centrados no indivíduo e em suas necessidades, em oposição a um formato no qual se capacita para um acesso a conteúdos que não lhe dizem respeito (Hartmann, 2010).

Outrossim, o problema da instauração de telecentros não se resume somente a questões de logísticas como dito acima, sua complexidade pode gerar situações imprevisíveis ao homem, como bem determinou Hartmann, agora reforçado por Mazoni (2009).

Se colocarmos hoje um telecentro em uma comunidade indígena, queremos que ela entenda a internet, considerando que hoje $80 \%$ do conteúdo da rede é em inglês e só 3\% é escrito em português e não há praticamente nada em guarani? Ou que possa usar a facilidade de comunicação, de interligação que pode estabelecer, por exemplo, com as 280 comunidades indígenas brasileiras espalhadas por esse continente que é o Brasil?

Outro exemplo: queremos colocar telecentros em uma favela para que as pessoas de lá recebam um modelo das elites brasileiras? Ou que elas entrem em um telecentro e mostrem o que fazem de cultura, de hip hop e outras coisas fantásticas? (p.5). 
Além desses percalços, a população e a sociedade brasileira ainda acaba tendo problemas de ordem ética ${ }^{41}$ que as vezes oriundos da perversidade do homem que prevalecem diante de garantias fundamentais previstas no ordenamento brasileiro.

Recente pesquisa realizada pela TIC Domicílios (divididos em 2 áreas: urbana e rural) em 2009 evidencia os "motivos pelos quais nunca utilizou a internet", dentre eles estavam em ordem decrescente: a falta de habilidade com o computador/Internet, não tem necessidade/interesse, não tem condições de pagar o acesso e não tem de onde acessar. (Brasil, n.d, 141). Ademais, a mesma pesquisa mostrou outro dado interessante; as habilidades ao uso da internet: em usar um mecanismo de busca de informações, enviar e-mail com arquivos anexados, enviar mensagens em salas de bate-papo, usar um programa para troca de filmes, músicas, criar uma página na web, usar a Internet para realizar ligações telefônicas e baixar e instalar softwares. (Brasil, n.d. p. 144) Tal pesquisa indica a iminente necessidade de se ampliar o projeto de educação digital para uma apropriação efetiva e mais aprimorada de tal tecnologia.

Sem querer desviar do escopo do ensaio, mas respalda-se em outro exemplo inquestionável da utilidade social dos telecentros quando se indaga o aspecto econômico com relação a questão do aumento do PIB e o incentivo aos micros e pequenos empreendedores ${ }^{42}$ como já é uma realidade, afirmado por Nivaldo Cleto (2010).

Uma das iniciativas fundamentais do Governo foi a criação dos Telecentros de Informações e Negócios - TINs, ambientes voltados para a oferta de cursos e treinamentos presenciais à distância, informações, serviços e oportunidade de negócios, visando o fortalecimento das condições de competitividade da microempresa e empresa de pequeno porte, e o estímulo à criação de novos empreendimentos. Serve como um instrumento para aproximar os empresários, as instituições públicas e privadas, as organizações não governamentais (ONGs) e a sociedade em geral. Composto por vários computadores interligados em rede local e conectados à internet, possuem orientação de monitores capacitados para atenderem às demandas de seus usuários (p. 76).

41 GLOBO.COM. (n.d.). Projeto de internet grátis em João Pessoa, anunciado em 2010, não funciona. Disponível em: <http://fantastico.globo.com/Jornalismo/FANT/0,MUL1679288-15605,00.html> 42 "A cada ano, das 134 mil empresas abertas no Estado de São Paulo, quase 88 mil não completam 12 meses de atividades. São 267 mil ocupações que deixam de existir - o equivalente a 3,3 estádios do Morumbi lotados - e uma perda financeira de R \$ 16 bilhões.”SEBRAE (n.d.) Disponível em:< http://www.biblioteca.sebrae. com.br/bds/bds.nsf/4BB33E51D81E5AE2832574E100742A84/\$File/NT00039182.pdf> 
Em diversos Estados brasileiros, a exemplo de São Paulo, os Telecentros têm surtido resultados acima do esperado. Os Telecentros desenvolvidos pela Prefeitura de São Paulo no "Plano de Inclusão Digital" incluem aulas de noções básicas de informática e Internet com voluntários e professores treinados pelo Governo Eletrônico - órgão da Secretaria de Comunicação Social. São 70 telecentros em bairros carentes de São Paulo. A meta paulistana é chegar à 1000 telecentros com um orçamento estimado em R\$2,8 milhões. (Mello, A. M. \& Campos, J. R. N. (2012).

Em Pinhais, cidade da região metropolitana de Curitiba, estado do Paraná, foram implantados 02 (dois) telecentros comunitários. Um deles localizado no bairro Maria Antonieta, anexo ao CAIC Marcelino Champagnat e, o outro no bairro Emiliano Perneta, na Escola Municipal Aroldo de Freitas. Tais telecentros que fornecem espaço público e gratuito às tecnologias da informação e comunicação, com computadores conectados à internet, difundem conhecimento aos que o procuram, são um grande exemplo que políticas públicas de inclusão digital podem dar certo, mesmo em cidades menores. (Dezembro, 2011,p. 15)

Oportuno são os números da Internet no Brasil, onde 43,1 milhões de pessoas têm acesso à internet a partir de qualquer ambiente, e desse total, aproximadamente 22 milhões o fazem em locais como lan houses, cibercafés e outros pontos pagos ou gratuitos, tais como escolas, segundo pesquisa do IBOPE em 2008. (Brasil, n.d, p. 26).

No entanto, segundo dados de outra pesquisa em 2009, o número de usuários de Internet que acessa a rede por telecentros têm crescido muito nas áreas rurais (4\% em 2008 e 6\% em 2009). Ademais os resultados da zona rural indicam que os telecentros tornaram-se ainda mais importante nessas regiões do país do que para as áreas urbanas. (Brasil, n.d, p. 117). Outro fenômeno interessante ocorreu com centros públicos pagos lanhouses em áreas rurais mostraram 54\%, passando 10 pontos percentuais dos $44 \%$ em área urbana, o que denota que o papel desempenhando pelos centros públicos de acesso pago e gratuito com agentes de inclusão na área rural, muito mais significativo que na área urbana.(Brasil, n.d, p. 133).

Logicamente que uma pesquisa realizada num curto período de tempo ou que mesmo em um ano não conseguiria auferir exatamente os gargalos ora em áreas urbanas, como rurais, ou se o acesso fora realizado em residências ou em locais de trabalho. Hartmann (2010) afirma: "o simples 'acessar' nada diz quanto à inclusão digital.” (p. 178). Como 
verificado, o poder público tem se preocupado em realizar a inclusão digital e políticas públicas a fim de se concretizar e efetivar direitos fundamentais, tais como o acesso à internet. É evidente também que os planos adotados, principalmente pelo governo federal, e em alguns casos, a nível estadual e municipal ainda não atingiram o resultado satisfatório aos anseios da população brasileira, devido ao desconhecimento ou uma falta de divulgação por parte do governo federal ou governos locais em revelar esses telecentros e abordar a sua utilidade $^{43}$. Mesmo sendo incipiente tais políticas públicas, é sempre importante acreditar em começos, já que a própria internet aconteceu por mero acidente de percurso, resultando nesse processo de massificação que ela é atualmente.

\section{CONCLUSÃO}

Não será uma tarefa fácil unir boa intenção política, eficácia e conscientização da sociedade. Como saber qual a fórmula ideal para que os indivíduos marginalizados possam ter acesso à rede mundial desmitificando seu uso?

Hoje não basta que o Estado seja solidário, sensível e simpatizante com o bem estar comum da sociedade, mas esses mesmos concidadãos devem ter a conscientização de quererem ter o acesso à informação e se valerem do conhecimento direcionado e específico, que lhe será útil para o seu desenvolvimento como pessoa humana. O coordenador da América Latina do programa Enlaces Mundiales para el desarrollo (World) prof. Jorge Gutierrez Martínez (2003) também compartilha da mesma linha de pensamento, senão vejamos

O acesso à grandes quantidades de informação não assegura a possibilidade de transformá-la em conhecimento. $\mathrm{O}$ conhecimento não viaja pela Internet. Construí-lo é uma tarefa complexa, para a qual não basta criar condições de acesso à informação. Hoje, para poder extrair informação útil do crescente oceano de dados acessível na Internet, exige-se um conhecimento básico do tema investigado, assim como estratégias e referenciais que permitam

43 “A média brasileira da população de 10 anos ou mais de idade, na faixa dos $40 \%$ mais pobres, que acessou a Internet por meio de telecentros é de pífio $0,9 \%$. Quando se considera apenas a região Sudoeste, todavia, o índice sobe para 1,5\%. No Estado de Alagoas as pessoas com essas características representam apenas $0,1 \%$. Já entre os 10\% mais ricos, os estudantes de 10 anos ou mais, cursando o Ensino Fundamental, que acessaram a Rede a partir da escola são 37,7\%". in WAISELFISZ, J. J. (2012). Instituto Sangari. Mapa das desigualdades sociais no Brasil. Disponível em: http:<www.institutosangari.org.br/ mapa_desigualdades_digitais.pdf $>$ 
identificar quais fontes são confiáveis. Por outro lado, não devemos esquecer que, para transformar a informação em conhecimento, exige-se - mais que qualquer outra coisa pensamento lógico, raciocínio e juízo crítico. (p. 96-97).

Temos que ter em mente que informação e conhecimento não são a mesma coisa, o fato de se criarem políticas públicas, tais como a brilhante iniciativa dos telecentros, pode redundar ao fracasso, haja vista que ter ferramentas estruturais, incentivo financeiro e uma equipe técnica pronta para ensinar, capacitar e distribuir o acesso à internet à comunidade, deve partir inicialmente das pessoas em terem o hábito, o costume e a cultura de querer ter acesso à esse mesmo "conhecimento", de preferência educativo, didático ou instrutivo, como o professor de história do direito da Universidade de Lisboa, Antonio Manuel Espanha ressaltou em sua entrevista, intitulada: "Mudar a lei é fácil. Difícil é reformar costumes". (Dedar, R., 2012). Um bom trabalho de divulgação com os meios de comunicação em massa, de iniciativa do governo federal e do poder político brasileiro em geral, é imperioso para a conclusão dessa árdua tarefa. Outrossim, de nada adianta criar espaços como esses (num ponto de vista da efetivação desse direito material) se as pessoas não souberem da existência dos mesmos, ou se ainda os utilizarem para práticas de jogos de computador, acessarem sites pornográficos ou lerem conteúdo inútil ou superficial, como já dito anteriormente.

A fim de concluir tal estudo invocamos as palavras de Jaime Vagner (2010) que na essência retrata o nosso apreço

Assim como a proximidade de uma escola ou de uma biblioteca não é indicador do nível de escolaridade ou de educação, a disponibilidade de banda larga, por si só, não garante a inclusão digital. $\mathrm{O}$ treinamento é fundamental para isso - e treinamento prático, não apenas teórico. (...) Portanto, é mister que a inclusão seja feita, de fato, e não somente nos dados estatísticos, a fim de que todos possam participar dela, usufruindo-a com autonomia. (p. 85).

“(...) É possível realizar os direitos fundamentais da Constituição, perseguindo essa idéia utópica, mas que enche de esperança, aqueles que estão inconformados com a realidade social do ser humano, em nosso País e no mundo." (Marcelo Antonio Theodoro) 


\section{REFERÊNCIAS BIBLIOGRÁFICAS}

Brasil (n.d). Guia das Cidades Digitais.

BrasiL. (n.d). Pesquisa sobre o uso das tecnologias da informação e da comunicação no Brasil TIC Domicílios e TIC Empresas 2009. CGI.BR (Comitê Gestor da Internet no Brasil), São Paulo.

Brasil. (n.d). $4 \mathrm{CMBr}$ Municípios Brasileiros: colaboração, comunidade, conhecimento e compartilhamento. $O$ que é um telecentro?. Disponível em: <http://www.softwarepublico.gov. $\mathrm{br} / 4 \mathrm{cmbr} /$ xowiki/o_que_e_telecentro $>$

Brito, G. Da S. \& Purificação, I. da. (2006). Educação e novas tecnologias: um repensar. Editora IBPEX, $1^{\mathrm{a}}$. edição, Curitiba.

Câmara Federal. (n.d). CCJ aprova admissibilidade de PEC sobre acesso a internet de banda larga: a proposta inclui o acesso a internet de alta velocidade entre os direitos fundamentais do cidadão na Constituição. Disponível em: http://www2.camara.gov.br/agencia/ noticias/COMUNICACAO/197765-CCJ-APROVA-ADMISSIBI LIDADE-DE-PEC-SOBRE-ACESSO-A-INTERNET-DE-BANDALARGA.html. p. 18-37h.

Canotilho, J. J. G. (1993). Direito Constitucional. Coimbra: Almedina.

Castells, M. (2006). A Era da informação: Economia, sociedade e cultura. 9. Ed. São Paulo: Paze Terra, v.1.

Cleto, N. (2010). Inclusão Digital dos pequenos e médios empreendedores do Brasil. in BRASIL. Pesquisa sobre o uso das tecnologias da informação e da comunicação no Brasil TIC Domicílios e TIC Empresas 2009. CGI.BR (Comitê Gestor da Internet no Brasil), São Paulo.

Coelho, L. F. (2004). Aulas de Introdução ao Direito, Barueri: Manole.

Compaine, B. M. (2001). Declare the war won. In: COMPAINE, B. M. (org.). The digital divide: facing a crisis or creating a myth? Cambridge (MA): MIT.

Cunha C. Da \& Werthein J. (2004). Educação e Conhecimento: a experiência dos que avançaram, Ministério da Educação, Brasília: 


\section{UNESCO.}

Deda, R. (2012). Gazeta do Povo. Democracia. "Mudar a lei é fácil. Difícil é reformar costumes". Disponível em: <http://www. $\mathrm{mp}$.pr.gov.br/modules/conteudo/ conteudo.php?conteudo=425>

Digitais, Guia das Cidades (n.d). Um leque de possibilidades. Março de 2009. Disponível em: <www.guiadascidadesigitais.com.br>

Digitais, Guia das Cidades (n.d). Em sintonia com um novo mundo. Março de 2009. Disponível em: <www.guiadascidadesigitais.com.br $>$

Dimoulis, D. \& Martins, L. (2008). Teoria Geral dos Direitos Fundamentais. Editora RT, São Paulo, 2a . tiragem.

Gardner, H. (1999). The Disciplined Mind. Nova Iorque: Simon and Schuster, 1999.

Globo.com. (n.d.). Projeto de internet grátis em João Pessoa, anunciado em 2010, não funciona. Disponível em: $<$ http://fantastico. globo.com/Jornalismo/FANT/ 0,,MUL1679288-15605,00.html>

Guiera, A. T. \& Tomizawa, G. (2011). A evasão de privacidade e a inversão de valores na sociedade pós-industrial. In: Aragão, P.; Romano, L. D.; Tayah, J. M. (coord.). Reflexiones sobre Derecho Latino Americano - Estudios en homenaje al Profesor Eduardo Barbarosch. Vol. 5. Buenos Aires: Editorial Quorum.

Hartmann, I. A. M. (2010). Ecodemoracia - a proteção do meio ambiente no ciberespaço, Porto Alegre: Livraria do Advogado Editora.

Hartmann, I. A. M. (2008). O acesso à internet como direito fundamental. Revista de Derecho Informático, n. 118, maio 2008. Disponível em: http://www.alfa-redi.org/rdi-articulo.shtml?x=10359

Hesse, K. (1991). A Força Normativa da Constituição. Porto alegre, Ed. Sergio Antonio Fabris.

Jellinek, G. System der Subjektiven Öffentlichen Rechte 1919. (1994), apud GAVARA de C., J. C. Derechos Fundamentales y desarollo legislativo: La garantia del contenido esencial de los derechos fundamentales em la Ley Fundamental de Bonn. Madrid: Centro de 
Estudios Constitucionales.

Lassale, F. (2009). A Essência da Constituição - 9a . edição. Editora Lumen Iuris, Rio de Janeiro.

Lévy, P. (2010). As Tecnologias da Inteligência, o futuro do pensamento na era da informática. $2^{\underline{a}}$. Edição, Editora 34, São Paulo.

LuñO, A. E. P. (1984). Los Derechos Fundamentales. Madrid, Tecnos, D.L.

Lyra Filho, R. (1995). O queé Direito? $17^{\mathrm{a}}$ ed., São Paulo: Brasiliense.

Malaquias, B. P. (2012). O Analfabetismo Digital. Instituto Brasileiro de Direito e Informática. Disponível em: <http://www.ibdi.org.br/site/ artigos.php? $\mathrm{id}=159>$

Martínez, J. H. G. (2003). Novas Tecnologias e o desafio da educação in Tedesco, Juan Carlos. Educação e novas tecnologias: esperança ou incerteza. (org.). Cortez Editora. São Paulo.

Mazoni, M. (2009). Digitais, Guia das Cidades. Tarefa de Todos. Março de 2009. Disponível em: <www.guiadascidadesigitais.com.br>

Mello, A. M. \& Campos, J. R. N. (2012). Ações sociais no combate à exclusão digital no Brasil. Disponível em: http://www.ead. fea.usp.br/semead $/ 7 \mathrm{semead} /$ paginas/ artigos\%20recebidos/Terceiro $\% 20$ Setor/TS02_A\%E7\%F5es_Sociais_no_Combate_a_Exclus $\%$ E3o Digit.PDF

Mendes, G. F. \& Coelho, I. M. \& Branco, P. G. G. (2008). Curso de Direito Constitucional. Editora Saraiva, $2^{\mathrm{a}}$. edição revista e atualizada. São Paulo.

Paesani, L. M. (2000). Direito e Internet: liberdade de informação, privacidade e responsabilidade civil. São Paulo: Atlas.

PEC inclui acesso à internet como direito social na Constituição. (n.d). Disponível em: <http://ultimainstancia.uol.com.br/conteudo/ noticias $/ 50580 / \mathrm{pec}+$ inclui + acesso $+\mathrm{a}+$ internet + como + direito + social + n a + constituicao.shtml $>$ 
Pereira, C. \& Betti, R. (2009). Os Tiranos da Internet: como o povo iraniano tem conseguido burlar o arsenal tecnológico dos aiatolás para bloquear o seu acesso à rede-e ao mundo. Revista VEJA, Editora Abril, $1^{\mathrm{o}}$ de julho.

Pinhais, Prefeitura Municipal de. (n.d). Inclusão Digital. Pinhais: Dezembro, 2011.

Sancho, J.M. y Hernández, F. (2000). Tecnologias para transformar a educação, Armed, São Paulo.

Scorzelli, P. (1997). A Comunidade Cibernética e o Direito. Editora Lumen Iuris, Rio de Janeiro.

Sebrae (n.d.) Disponível em:< http://www.biblioteca.sebrae. com.br/bds/ bds.nsf/4BB33E51D81E5AE2832574E100742A84/ \$File/NT00039182.pdf>

Silva, J. A da. (1998). Aplicabilidade das normas constitucionais. $3^{\mathrm{a}}$. Ed. São Paulo: Malheiros.

Tedesco, J. C. (2003). Educação e novas tecnologias: esperança ou incerteza. (org.). Cortez Editora. São Paulo.

Theodoro, M. A. (2002). Direitos fundamentais e sua concretização. Editora Juruá, Curitiba.

Tomizawa, G. (2008). A invasão de privacidade através da internet. Curitiba: JM Livraria Jurídica.

Tomizawa, G. (2012). O Direito à privacidade e a intromissão estatal através dos sistemas de inteligência e ferramentas de espionagem dentro da Internet. ANIMA V - Revista de Direito Eletrônico do Curso de Direito da OPET. ISSN 2175-7119, Volume 5, série 5, págs. 302-316. Disponível em: http://www.anima-opet.com.br/pdf/anima5Professores/GUILHERME-TOMIZAWA-ANIMA5.pdf

UOL (n.d). PEC inclui acesso à internet como direito social na Constituição. Disponível em: <http://ultimainstancia.uol.com.br/ conteudo/noticias $/ 50580 / \mathrm{pec}+$ inclui + acesso $+\mathrm{a}+$ internet + como + direito + social + na + constituicao.shtml $>$ 
Vieira, T. M. (2007). O Direito à privacidade na sociedade da informação: efetividade desse direito fundamental diante dos avanços da tecnologia da informação. Sergio Antonio Fabris Editor, Porto Alegre.

Wagner, J. (2010). Pesquisa sobre o uso das tecnologias da informação e da comunicação no Brasil TIC Domicílios e TIC Empresas 2009: o pnbl $e$ os pequenos provedores. CGI.BR (Comitê Gestor da Internet no Brasil), São Paulo.

Waiselfisz, J. J. (2012). Instituto Sangari. Mapa das desigualdades sociais no Brasil. Disponível em: http:<www.institutosangari.org.br/ mapa_desigualdades_digitais.pdf $>$

Weinberg, M. (2012). 7 lições da Coréia para o Brasil: O que o país pode aprender com o bem-sucedido modelo de educação implantado na Coréia do Sul. VEJA on-line. Disponível em:<http://veja.abril.com.br/ 160205/p_060.html>

Wikipedia. (n.d). Disponível em: <http://pt.wikipedia.org/ wiki/Internet>.

Wikipedia. (n.d). Disponível em: <http://pt.wikipedia.org/wiki/ Exclus\%C3\% A3o_digital> 